mgr Katarzyna Zielińska

Akademia Sztuk Pięknych im. Jana Matejki w Krakowie

O UPOWSZECHNIANIU KULTURY W CZASIE PANDEMII.

METODY DZIALAŃ W SEKTORZE WYSTAWIENNICTWA

\title{
Artykul przeglądowy
}

\section{Spis treści}

Abstrakt 38

Słowa klucze 38

Wstęp 39

Instytucje kultury w czasie pandemii 39

Zamknięte galerie | otwarte wystawy - przemodelowanie sposobu docierania do odbiorcy 40 Upowszechnianie kultury - nowe metody działań 40

Czy sztuka w czasie pandemii jest nam potrzebna? 46

Bibliografia 48 
TOM 2 (2021), NR 1

\begin{abstract}
Abstrakt
Przeobrażenia naszej codzienności, które nastąpiły za sprawą ogólnoświatowej pandemii wywołanej przez COVID-19, mocno zreorganizowały wiele płaszczyzn naszego życia, do których specyfiki dotychczas przywykliśmy. Zagadnienie to jest wyraźnie widoczne także na płaszczyźnie artystycznej. Przez brak możliwości organizowania wydarzeń, wspólnych spotkań kulturalnych mocno przekształcił się charakter popularyzowania kultury, wydobywając nowe metody działań, niejednokrotnie wchodzących w silną dygresję z pierwotnym celem twórczości, jakim jest bezpośredni kontakt odbiorcy ze sztuką. Artykuł stanowi próbę odpowiedzi na pytanie: „Jak sobie z tym poradziliśmy?”.

Artykuł zgłębia problem, skupiając się na analizie retrospektywnej i bieżącej wybranych działań w zakresie rozpowszechniania i promocji sztuki różnego rodzaju, odbywających się w obliczu przemodelowania rzeczywistości wywołanej wprowadzonymi obostrzeniami epidemiologicznymi. Analiza poparta jest przykładami aktywności sektora popularyzacji kultury i sztuki, zaistniałymi w reakcji na nagły lockdown, między innymi także działań odbywających się w Galerii Fashion Start-up Gallery, funkcjonującej przy Wydziale Architektury Wnętrz Akademii Sztuk Pięknych im. Jana Matejki w Krakowie, powstałej dzięki realizacji projektu „Projektowanie Przyszłości - program rozwoju Akademii Sztuk Pięknych im. Jana Matejki w Krakowie na lata 2018-2022”. W wyniku analizy określone zostały zmiany, narzędzia i ich rodzaje, które posłużyły w przemodelowaniu aktywności w sferze upowszechniania kultury, polegające na wielorakiej ekspozycji dzieła dla odbiorcy.
\end{abstract}

\title{
Słowa klucze
}

wystawiennictwo, ekspozycje, zmiany, COVID-19, immersja, digitalizacja, transmisja, online, web, upowszechnianie, nowe media, nowa technologia, potrzeby, myśli, transfer, nowa rzeczywistość, networking, online viewing room, connection, cyberspace, interfejs, dostęp, izolacja, postęp, przestrzeń, mgła, czas, virtual 
TOM 2 (2021), NR 1

\section{Wstęp}

Pandemia zreorganizowała całkowicie sposób korzystania z kultury. W momencie powstawania tego artykułu minął już niemal rok, od kiedy przez cały czas, mniej lub bardziej nieprzerwanie, próbujemy zmierzyć się z nową rzeczywistością na prawie każdej płaszczyźnie naszego życia. Z pewnością do niektórych aspektów już przywykliśmy, przyswoiliśmy je, jednak pośrednio wciąż buduje się w nas szereg reakcji na zaistniałą sytuację. W pierwszym odruchu często pojawia się w nas niepewność, wywołana przez nowe, nieznane w takiej skali zagrożenie, często przeradzająca się w narastający strach. W efekcie tego, niepewni jutra, podporządkowujemy się nowym obostrzeniom. Zostajemy w domu. Oczekując, ciągle nie możemy być pewni niczego, co w najbliższym czasie przyniesie przyszłość - stabilność sytuacji przez długi czas nie jest jasna. Całe swoje życie w większości zamykamy w czterech ścianach. Musimy nauczyć się panować nad spokojem każdego dnia. Rodzi to w nas uczucie bezsilności, czasem wywołującej odruchy paniki lub buntu wobec nowej sytuacji. Nic nie jest takie jak wcześniej, zaczynamy przyjmować codzienność w kompletnie nowej formie...

W reakcji na nagły lockdown nastąpiło drastycznie szybkie wyłączenie z funkcjonowania instytucji upowszechniających kulturę i sztukę. Artyści stracili możliwość przedstawiania swoich dzieł stacjonarnie szerszemu gronu odbiorców. Oddaliliśmy się od przedpandemicznego pojęcia autentyczności, mającej wpływ na sposób, w jaki reagujemy na sztukę. Odróżniając realność od wirtualności, autentyczność i wartość jako niematerialne parametry stały się nad wyraz istotne ${ }^{1}$.

\section{Instytucje kultury w czasie pandemii}

Zamknięcie galerii sztuki czy muzeów odebrało możliwość przeżywania, doświadczania kultury in situ, odbierając nam w ten sposób najważniejszą wartość, jaką niesie obcowanie z dziełem - możliwość przeżywania go tu i teraz, stykając się z oryginalną, pierwotną materią dzieła w autentycznej strukturze. Nie da się jednak zaprzeczyć, że temat ogólnoświatowej pandemii to z drugiej strony w późniejszym etapie także szeroki obszar poszukiwań, znajdujący odzwierciedlenie w twórczości artystów, podsumowujących w ten sposób doświadczenie odosobnienia, w efekcie powodującego także pobudzenie skrywanych wewnątrz lęków czy aspiracji ${ }^{2}$. Jak podaje Raport Kultura, aż 59,1\% instytucji wykazało, że dotknęły je skutki pandemii już w drugim kwartale 2020 roku³ $^{3}$

$1 \quad$ Michael Bird, 100 idei, które zmienity sztukę, TMC, Raszyn, 2012, s. 198.

2 Alain de Botton, Architektura szczęścia, Czuły Barbarzyńca, Warszawa, 2010, s. 103.

3 Raport Kultura, Fundacja Gospodarki i Administracji Publicznej, Kraków 2020, s. 11. 


\section{Zamknięte galerie | otwarte wystawy - przemodelowanie sposobu docierania do odbiorcy}

Wejście sztuki w sferę cyfrową było w tym wypadku nieuniknione. Często stawało się jedynym sposobem na prezentację twórczości. Zaznaczyć należy, że galerie nie ograniczają się już jedynie do powierzchni będących różnego rodzaju przestrzeniami ekspozycyjnymi. Często znajdujemy w tego typu obiektach także sale do przedstawień teatralnych czy performance'ów, audytoria do spotkań z twórcami lub pokazów filmowych, koncertów oraz szereg innych funkcji, które sprawiają, że galeria komercyjna staje się swoistym konglomeratem twórczości. Zauważenie i odpowiednie określenie pojawiających się trudności wywołanych pandemią powoduje odpowiednie dobranie metod nowego sposobu docierania do odbiorcy.

Mimo dużej powierzchni wystawienniczej, najważniejszymi fizycznie (i często jedynymi) nośnikami treści, łącznikami instytucji z odbiorcą w czasie pandemii stały się witryny, okna, portale. W pierwszych działaniach właśnie one były głównym medium przekazującym treść. Uzależnienie się od charakterystyki danej przestrzeni wystawienniczej przestało mieć większe znaczenie, gdyż nie można było jej fizycznie wykorzystywać ${ }^{4}$.

Szybka diagnoza pewnych strategii spowodowała jednak, że mimo zamknięcia instytucji wydarzenia nadal pozostały żywe, rearanżując się w nowej formie, nowej technice, nowej rzeczywistości. W czasie pandemii technologia - oraz to, jak ją wykorzystujemy - postąpiła o wiele intensywniej, niż mogłoby się to dziać w normalnych warunkach.

Być może w niektórych wypadkach nadmierna chęć wzbudzenia zainteresowania poprzez docieranie do odbiorcy na wielu nowych płaszczyznach sprawiała wrażenie, że sztuka staje się bardziej komercyjna, marketingowa. Niewątpliwie jednak udało się dzięki temu utrzymać osiągnięty w nieco innej formie rezultat wpływu i renomy instytucji, które musiały pozostać przez pewien czas zamknięte. Zdaliśmy sobie sprawę, jak ważna jest obecność.

\section{Upowszechnianie kultury - nowe metody dzialań}

Z pomocą przyszła nam technologia. Dzięki postępowi mogliśmy w stopniu umożliwiającym chociażby podstawowe czynności kontynuować naszą pracę, nasze hobby i pasje.

W ostatnim dziesięcioleciu wskutek wzrostu zamożności społeczeństwa sztuka stała się rozumiana jako luksusowe dobro, wzrósł ,popyt na sztukę”, wskutek czego wszelkiego rodzaju targi czy aukcje znacząco zyskały na popularności. W obliczu obostrzeń niestety sukcesywnie zamykana została większość domów aukcyjnych, targów czy festiwali sztuki, będących dotychczas popularnym 
TOM 2 (2021), NR 1

medium dla nabywców dzieł. Już w pierwszym kwartale 2020 roku anulowane zostały ogólnoświatowe wydarzenia, takie jak targi sztuki w Tokio, wydarzenie Art Dubai czy największe na świecie targi sztuki współczesnej Art Basel. W efekcie niemożliwości przeprowadzenia stacjonarnego wydarzenia zaproponowano umieszczenie dzieł sztuki w nowej platformie cyfrowej, tak zwanym online viewing room $^{5}$. Jest to trójwymiarowa, zdigitalizowana wersja fizycznego miejsca, w którym mielibyśmy docelowo oglądać sztukę w pierwotnej formie. Daje ona nabywcy namiastkę prawdziwego wydarzenia. Online viewing room to pozornie zaprogramowane pomieszczenie, wirtualnie mieszczące jedno lub maksymalnie kilka dzieł, dzięki czemu ich ekspozycja staje się także bardziej indywidualna oraz atrakcyjna niż w przypadku standardowych warunków, w których najczęściej jest to duża przestrzeń ekspozycyjna, skupiająca w sobie wszystkie dzieła ${ }^{6}$.

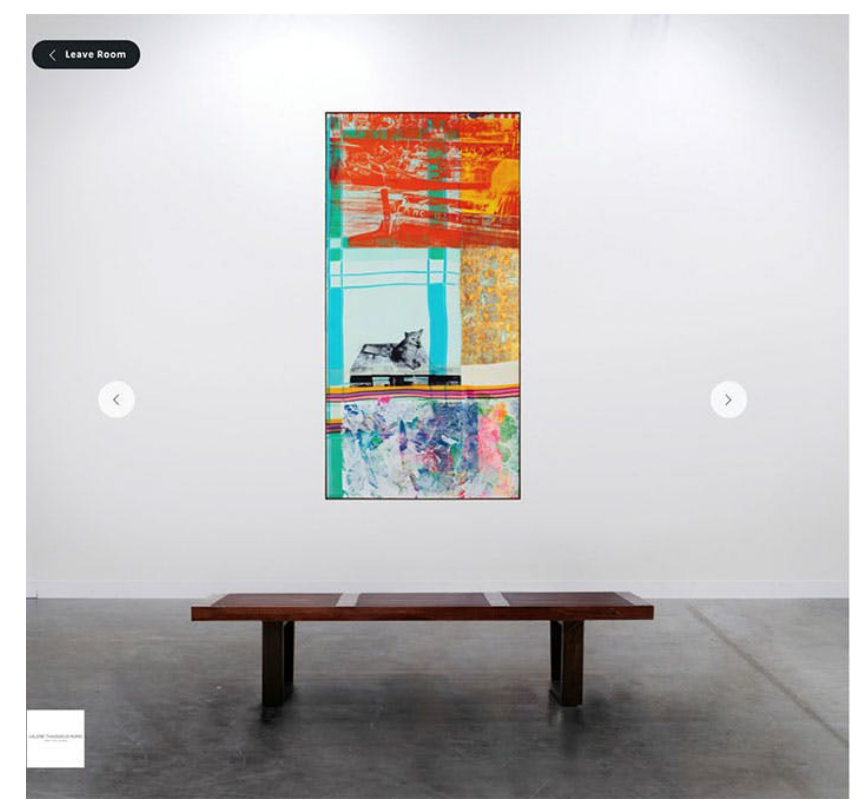

Il. 1. Screenshot of Galerie Thaddaeus Ropac's online viewing room, Art Basel Hong, March 2020, courtesy Art Basel Hong Kong, https://apollo.imgix.net [dostęp: 21.05.2021].

Do tej pory technika prezentacji sztuki w myśl idei online viewing room rozwinęła się do poziomu projektowania w sieci całych wirtualnych ekspozycji. W przypadkach niektórych aukcji, jak na przykład podczas Asia Week odbywającego się w marcu, łączono tradycyjne formy sprzedaży ze sprzedażą online. Aukcja południowoazjatyckiej sztuki współczesnej organizowana w ten sposób odniosła sukces - wartość sprzedanych dzieł przewyższyła pierwotne szacunki o 100 tysięcy dolarów, dając wynik 4,8 milionów dolarów. 33\% dzieł z tej aukcji zostało sprzedanych poprzez licytacje online ${ }^{7}$. Okazało się, że tego rodzaju dywersyfikacja, hybrydowość działań, pozwalająca łączyć metody tradycyjne z tymi, na które pozwala nam technologia, staje się coraz bardziej powszechna i z pewnością 
TOM 2 (2021), NR 1

pozostanie przyjęta jako standard. Dowodem na to jest także fakt, że - jak dowiodły przeprowadzone w 2020 roku badania - sprzedaż dzieł na polskim rynku sztuki była o 30\% wyższa aniżeli w roku $2019^{8}$.

[...] rynek osiągnął rekordowy wynik $380 \mathrm{mln}$ zł. Przeprowadzono 467 aukcji, wiele online, podczas których wylicytowano niemal 22 tys. obiektów. W grudniu padł rekord sprzedaży w segmencie sztuki nowoczesnej - obraz Wojciecha Fangora został wylicytowany za najwyższą w historii cenę 7,3 $\mathrm{mln}$ zł’.

Nie tylko czas pandemii, ale już lata przed jej początkiem pokazują, że coraz większa liczba potencjalnych nabywców sztuki decyduje się na zakup online. Chociaż także w przypadku tradycyjnych aukcji wiele licytacji miało miejsce poza wydarzeniem, z pewnością upowszechnianie tego typu działań online stanie się normą w przyszłości. Ulepszanie możliwości nabycia różnego rodzaju dzieł za pośrednictwem sieci staje się dodatkową alternatywą dla kupującego, który niejednokrotnie nie mógłby uczestniczyć osobiście w tego typu wydarzeniach, chociażby ze względu na konieczność przemieszczania się. Jest to także korzyść dla galerii, domów aukcyjnych oraz samych artystów, którzy mogą promować i sprzedawać swoje prace.

Wychodząc naprzeciw nagłym ograniczeniom, galerie sztuki, muzea, kina, teatry, opery czy filharmonie rozpoczęły szereg eksperymentów z użyciem nowych technologii, pozwalających odbiorcom na wirtualne zwiedzanie ekspozycji, uczestnictwo w wydarzeniach, pokazach, prelekcjach. Poprzez zanik dotychczasowych sposobów działalności wiele dyscyplin zostało przeklasyfikowanych pod kątem nowego sposobu dostępności dla odbiorcy, pozbawionego możliwości fizycznej obecności.

Zamknięcie instytucji nie jest już przeszkodą w zwiedzaniu wystaw, mimo całkowitego lub częściowego ograniczania zwiedzania, nie jest to czas stagnacji. Obecnie niejednokrotnie mamy możliwość zobaczenia ekspozycji na wielu płaszczyznach. Sama aranżacja wydarzenia w sieci może być prowadzona wielotorowo i uwzględniać nie tylko strony internetowe, ale także media społecznościowe, komunikatory. Wydarzenie może odbyć się bez udziału publiczności, ale z pełnym do niego dostępem dla wszystkich, którzy chcą zobaczyć je online.

Fotorealistyczne odwzorowanie w postaci wirtualnych spacerów znane jest już od lat, choćby dzięki platformie Google, jednak ich specyfika w ostatnim czasie zaczęła się mocno pogłębiać. Dzięki możliwościom, jakie ze sobą niosą, odwiedzamy już nie tylko wystawy, ale także inne miejsca, niosące ze sobą określoną wartość dla odbiorcy. Projektowane w ten sposób wirtualne zwiedzanie tworzy z góry założoną strukturę informacji, zapewnia zachowanie określonej chronologii i proporcji eksplorowanej przestrzeni. Kontrola nad nawigacją widza jest bardzo precyzyjna. Podobną zasadę działania przyjmuje idea skanowania wystaw, polegająca na osadzaniu w konkretnej lokalizacji wirtualnie przeskanowanej przestrzeni jej zdjęć panoramicznych. Zarówno spacer online, jak i zwiedzanie

\begin{tabular}{ll}
\hline 8 & https://artinfo.pl. \\
9 & https://biznes.newseria.pl.
\end{tabular}


TOM 2 (2021), NR 1

za pomocą skanowania 3D umożliwia bardzo wnikliwe zapoznanie się z prezentowanym obiektem poprzez możliwość rozszerzenia informacji w dowolnym momencie mamy możliwość zaznajomienia się ze wszystkim, co go dotyczy, w różnym formacie cyfrowym. Jest to nieograniczony sposób na dostarczanie informacji o obiekcie czy miejscu. Jedną z bogatszych prezentacji w Polsce udostępnionych w ten sposób online jest zbiór Muzeum Narodowego w Krakowie, które udostępniło ponad 130 tys. dzieł ${ }^{10}$.

Niektóre przestrzenie można oglądać także za pomocą wirtualnej rzeczywistości (VR). Zakładając na przykład okulary VR Google, możemy cyfrowo przenieść się w inne otoczenie. Stanowi to kolejną, bardzo rozbudowaną drogę do poznawania tego, z czym nie możemy zetknąć się w rzeczywistości. Technologia Virtual Reality daje możliwość manipulacji przestrzenią, zmieniania jej w zależności od naszych potrzeb, uznania.

Czas pandemii to czas działania za pośrednictwem ekranów, to znaczy obrazowo. Postępową formę przybrały także różnego typu wydarzenia - wernisaże, prelekcje, konferencje. Technika live stream pozwalała na przeprowadzenie niemal nienaruszonej formy dla prelegentów, bez udziału obserwatorów, którzy mieli jedynie wirtualny dostęp do treści.

Nowe formy wernisaży, zwiedzanie dzięki wirtualnym spacerom czy skanowanie przestrzeni to jedynie część zabiegów mających na celu polepszenie dostępności ekspozycji dla odbiorcy. Wszystkiemu akompaniują dodatkowo wydarzenia towarzyszące, zwykle równie łatwo dostępne w internecie wywiady z twórcami, aranżacja całych wydarzeń w sieci, dostęp do różnego rodzaju prelekcji, organizowane są warsztaty online czy konferencje. Mamy możliwość analizy i pomiaru między innymi wyświetleń i ich obszaru.

Wraz ze zmianą sposobu przekazu zmieniły się także emocje, towarzyszące nam w postrzeganiu sztuki. Sztuka zbliżyła się do nas, stając się bardziej przystępna. Poczucie wzniosłości wywołane szeregiem bodźców powstałych w reakcji na zaprojektowane przestrzenie ekspozycji bywało sprowadzone do dostępności na ekranie.

Dopiero w swoim zbliżeniu do prawdziwego ludzkiego życia toczącego się poza pracowniami, galeriami sztuki i domami aukcyjnymi sztuka może stać się czymś żywym, pociągającym i fascynującym¹1.

W życie wchodzi coraz więcej różnorodnych pomysłów dotyczących przedstawienia życia w trakcie pandemii. Muzeum Narodowe w Krakowie w październiku 2020 roku podjęło inicjatywę zbierania atrefaktów związanych z pandemią na rzecz planowanej wystawy dotyczącej tego trudnego czasu w historii miasta i jego mieszkańców. Z podobną inicjatywą wyszło Victoria and Albert Museum, tworząc wirtualną wystawę Now Accepting Contactless czy Pandemic objects obrazującą, jak

11 Alicja Rybkowska, Humor a współczesna kondycja sztuki, Universitas, Kraków, 2016, s. 33. 
TOM 2 (2021), NR 1

zmieniły się wartość, cel i znaczenie przedmiotów, którymi się otaczamy, elementów codziennego życia w obliczu pilnej potrzeby odpowiedzi na nowe zagrożenie ${ }^{12}$.

Sposób popularyzacji sztuki w czasie pandemii stał się niemalże nurtem, programem, medium prezentującym ówczesny, jakże specyficzny, tok rzeczywistości ${ }^{13}$.

Poniżej przytoczone zostały dwa przykłady działań z zakresu wystawiennictwa, na które bezpośredni wpływ miała pandemia COVID-19. Wydarzenia odbywały się w Galerii Fashion Start-up Gallery, funkcjonującej przy Wydziale Architektury Wnętrz Akademii Sztuk Pięknych im. Jana Matejki w Krakowie, powstałej w ramach realizacji projektu „Projektowanie Przyszłości - program rozwoju Akademii Sztuk Pięknych im. Jana Matejki w Krakowie na lata 2018-2022”.

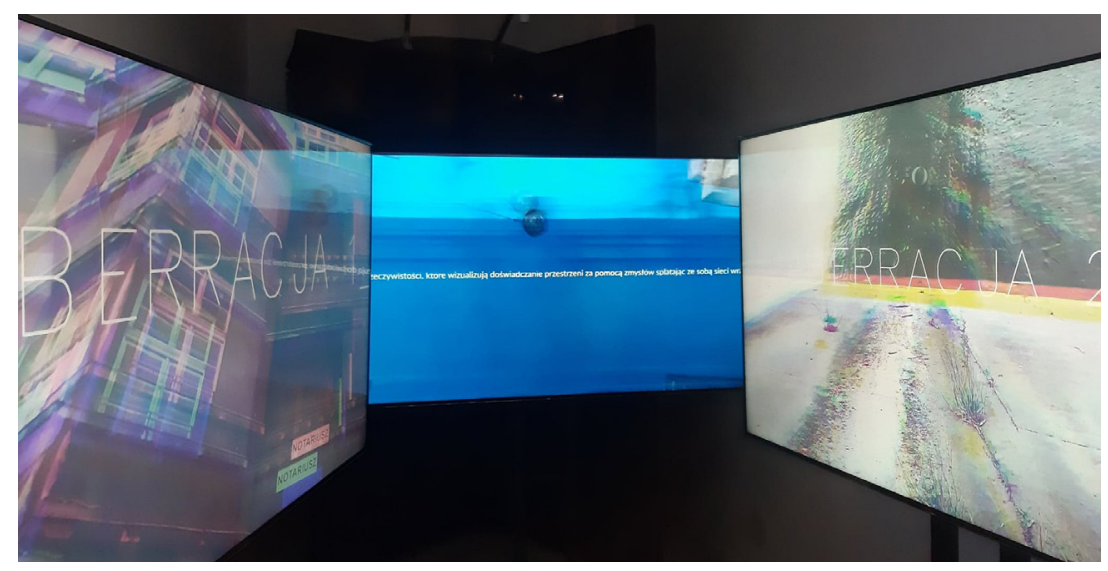

Il. 2. Projekt Aberracje, aut. dr Partycja Ochman-Tarka, mgr Paulina Ochman, prezentowany w Fashion Start-up Gallery w ramach festiwalu Cracow Art Week - KRAKERS, sekcja Fringe (prezentacja w dniach 21.10.-3.11.2020).

W ramach corocznego festiwalu KRAKERS Cracow Art Week w Fashion Start-up Gallery w październiku 2020 roku zaplanowana została prezentacja projektu Aberracje - instalacji multimedialnej autorstwa dr Patrycji Ochman-Tarki oraz mgr Pauliny Ochman. Projekt ten był multisensorycznym tworem, łączącym w sobie elementy projekcji wideo, interakcji z odbiorcą poprzez reakcję na ruch, co dawało możliwość manipulacji przestrzenią, rozciągania jej, defragmentacji, zwielokrotnienia... Wprowadzone obostrzenia nie pozwoliły jednak w pełni zrealizować tego zamysłu w pierwotnej formie. Ograniczenie liczby zwiedzających lub całkowity brak możliwości wejścia do galerii wiązał się z potrzebą rearanżacji pomysłu i przystosowania go do nowej rzeczywistości. Finalnie wszelkie działania mające zadziać się w fizycznej przestrzeni po interakcji wywołanej ruchem odbiorcy zostały efektywnie przedstawione za pomocą projekcji multimedialnej w trzech częściach.

13 Małgorzata Litwinowicz-Droździel, Iwona Kurz, Paweł Rodak, Ekspozycje nowoczesności, Neriton, Warszawa, 2017, s. $167-168$. 
TOM 2 (2021), NR 1

Projekt Aberracje niesie ze sobą włókna realnej rzeczywistości, które wizualizują doświadczanie przestrzeni za pomocą zmysłów, splatając ze sobą sieci wrażeń i fragmenty świata dostępnego poznaniu zmysłowemu ${ }^{14}$.

Innym przykładem wdrożenia nowego działania w strukturę aktywności Fashion Start-up Gallery jest sposób komunikowania się twórców z odbiorcą poprzez nową formę organizowania wydarzeń. Obostrzenia regulujące liczbę osób w danym pomieszczeniu nie pozwalają na swobodne organizowanie choćby wernisaży czy finisaży wystaw w znanej dotychczas formie. Sama idea wernisażu jako formy otwarcia wystawy czy wydarzenia będącego okazją do wspólnego spotkania celem kontemplacji twórczości została mocno naruszona. Zaplanowany w połowie listopada 2020 roku wernisaż wystawy rysunków kolorowych autorstwa prof. Stanisława Tabisza Na-Stroje jednorożca ze względu na obostrzenia nie mógł odbyć się z udziałem szerszego grona odwiedzających. W reakcji na powyższy problem, dzięki powszechnym już w tym czasie możliwościom video-streamingu, zorganizowana została transmisja online z wernisażu, który odbył się fizycznie w najmniejszym możliwym gronie osób, przy zachowaniu w ten sposób wszelkich obostrzeń. Możliwości streamingu na wielu kanałach wraz z zapisem obrazu umożliwiły obejrzenie otwarcia wystawy oraz autorskiego oprowadzania osobom, które niejednokrotnie nie miałyby nawet możliwości odwiedzenia wystawy na miejscu. Nagranie daje możliwość zapoznania się z relacją osobom, które w tym czasie nie mogły w niej uczestniczyć. Taki sposób prezentacji wydarzenia z pewnością wplecie się na dobre w zestaw działań promujących wydarzenia kulturalne. Na wystawie zaprezentowano ponad 70 rysunków, w efekcie czego stworzona została także wirtualna galeria zawierająca skany wysokiej rozdzielczości każdego z nich.

Liczne przedsięwzięcia związane z wprowadzonymi obostrzeniami podjęły także między innymi teatry. W tym wypadku sytuacja jest jednak znacznie poważniejsza, gdyż wraz z brakiem możliwości odgrywania spektakli wiąże się brak pracy dla osób zaangażowanych w realizację sztuki na każdym poziomie. Ciekawym przykładem sposobu umożliwienia widzom doświadczania sztuki teatralnej w obliczu pandemii jest inicjatywa japońskiego teatru Moonlight Mobile Theater. Jak tłumaczy Nobuyoshi Asai, dyrektor artystyczny teatru i choreograf, widzowie mają możliwość oglądania awangardowej sztuki przez otwór na listy w symbolicznych drzwiach, siedząc w wydzielonych boksach wokół okrągłej sceny, na której prezentują swój spektakl aktorzy. Instalacja umożliwia nowe doświadczenie oglądania performance'u 30 osobom równocześnie ${ }^{15}$. Oczywiście nie da się w ten sposób uzyskać zysku takiego jak przy standardowym formacie spektaklu, jednak z drugiej strony tego rodzaju eksperyment to jedyny sposób na aktywność zawodową nie tylko dla aktorów, ale również choreografów, scenarzystów, reżyserów, a także niezwykła okazja do rozreklamowania swojej działalności na duża skalę - bilety na wszystkie przedstawienia teatru wyprzedały się błyskawicznie. 
TOM 2 (2021), NR 1

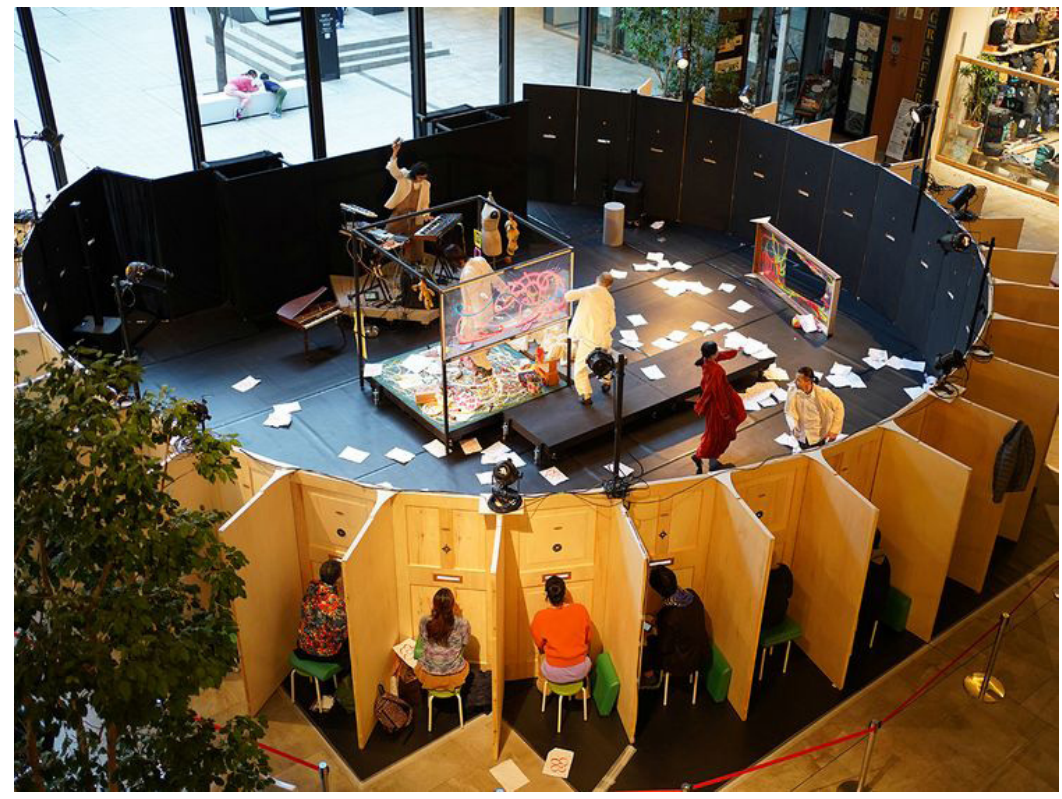

Il. 3. Spektakl teatru tanecznego Moonlight Mobile Theater, Japonia - forma doświadczania spektaklu jest wynikiem ograniczeń wprowadzonych w związku z ogólnoświatową pandemią COVID-19, https://gulfnews.com/world/offbeat/through-the-mailbox-slot-japanese-theatre-offers-new-viewing-experience-1.1614701494277 [dostęp: 21.05.2021].

Konkluzja powyższych przytoczeń może rodzić stwierdzenie, że kultura cyfrowa stała się kulturą powszechnego i łatwego dostępu. Z pewnością tak jest, nie możemy jednak zapomnieć, że dla osób, które nie mają dostępu do odpowiednich urządzeń czy też nie mają umiejętności, aby je obsłużyć, lub po prostu żyją w miejscach, gdzie łączność jest utrudniona, może spowodować to większy dyskomfort.

\section{Czy sztuka w czasie pandemii jest nam potrzebna?}

Brak dostępności do podmiotów publicznych takich jak galerie czy muzea, ale także wydarzenia z zakresu sektora sztuki, sprawił, że materialna sztuka zaistniała bardzo wyraźnie w świecie wirtualnym, który stał się jej niemal jedynym medium poznawczym w tym czasie. Branża artystyczna wyraźnie ucierpiała, lecz z drugiej strony był to dla artystów czas niezwykle twórczy. Dynamizacja i rozrost sposobów działań w sferze online przybrały niespotykaną dotąd skalę. Przeniesienie działań w przestrzeń multimedialną wywołuje jednak wciąż różnorakie odczucia. $Z$ jednej strony, odbierając istotę obcowania z dziełem, burzy pierwotnie pożądaną relację z odbiorcą, uniemożliwiając dostąpienia pełni doznań estetycznych wynikających z bezpośredniego kontaktu z dziełem. Z drugiej jednak strony, rozwija nieograniczone możliwości upowszechniania twórczości w sferze wirtualnej, tworząc sposobność zaistnienia tam, gdzie dzieło nie trafiłoby nigdy w swojej pierwotnej formie.

Nie da się ukryć, że robimy wszystko, aby sztuka nie zniknęła z naszego życia. Szukając metod, eksperymentujemy, dostarczamy bodźców bezpośrednio lub pośrednio pobudzających zakres naszej 
aktywności. Opracowujemy modele funkcjonowania, które pozwalają nam osadzić różnorodność naszych działań w nowym świecie. Kulturotwórcza misja miejsc, dzięki którym możemy doświadczać wielowymiarowej sztuki, pozwala nam zaczerpnąć jej w najprawdziwszej swojej istocie. Niejednokrotnie dowiedziono, że kultura to ogniwo, które jako pewna składowa powiązań i współzależności naszego życia zapobiega społecznemu kryzysowi ${ }^{16}$. Ciągle obserwujemy rozrost nowych metod upowszechniania kultury. Dzięki temu możemy śmiało stwierdzić, że piękno wpływa na jakość naszego życia, a sztuka jest jego nierozerwalną częścią, funkcjonującą w nas być może w różnym natężeniu, jednak niezmiennie.

Należy pamiętać jednak, że nie tylko powinniśmy się zastanawiać, jak ciągle na nowo dopasowywać się do pandemicznej rzeczywistości, ale także zadać sobie pytanie, jak będziemy potrafili znowu żyć ze sobą nawzajem, gdy ten trudny czas już dobiegnie końca. 


\section{Bibliografia}

Bird Michael, 100 idei, które zmienity sztukę, TMC, Raszyn 2012.

Botton Alain, de, Architektura szczęścia, Czuły Barbarzyńca, Warszawa 2010.

Gołaszewska Maria, Estetyka i antyestetyka, Wiedza Powszechna, Warszawa 1984.

Hussakowska-Szyszko Maria, Tatar Ewa Małgorzata, Display. Strategie wystawiania, Universitas, Kraków 2012.

Litwinowicz-Droździel Małgorzata, Kurz Iwona, Rodak Paweł, Ekspozycje nowoczesności, Neriton, Warszawa 2017.

Raport Kultura, Fundacja Gospodarki i Administracji Publicznej, Kraków 2020.

Rybkowska Alicja, Humor a współczesna kondycja sztuki, Universitas, Kraków 2016. 
TOM 2 (2021), NR 1

Utwór udostępniany na licencji Creative Commons Uznanie autorstwa 4.0 Międzynarodowe

Artykuł recenzowany

Wydawca: Akademia Sztuk Pięknych im. Jana Matejki w Krakowie, Wydzial Architektury Wnętrz

Redakcja: prof. dr hab. Beata Gibala-Kapecka, dr Joanna Lapińska

Opracowanie graficzne: Joanna Łapińska

Fotografia na stronie tytułowej: Katarzyna Zielińska

Czasopismo „inAW Journal - Multidisciplinary Academic Magazine” powstało dzięki dofinansowaniu w ramach projektu „Projektowanie przyszłości - program rozwoju Akademii im. Jana Matejki w Krakowie na lata 2008-2022” 